\title{
DESIGN OF EXPERIMENT (DOE) LIQUID PHOTOIMAGEABLE SOLDER MASKS PCB PADA TEACHING FACTORY MANUFACTURING OF ELECTRONICS (TFME) POLITEKNIK NEGERI
} BATAM

\author{
Nadhrah Wivanius*, Nur Sakinah Asaad*, Heru Wijanarko ${ }^{\#}$, dan Ira Zamzami ${ }^{\circledR}$ \\ Politeknik Negeri Batam \\ * Program Studi Teknik Elektronika Manufaktur \\ \# Program Studi Teknik Mekatronika \\ @ Program Studi Teknik Elektronika \\ Jl. Ahmad Yani Batam Kota. Kota Batam. Kepulauan Riau. 29461. Indonesia \\ E-mail: wijanarko@polibatam.ac.id
}

\begin{abstract}
Abstrak
Makalah ini mengkaji beberapa variabel untuk mencari paramater yang paling baik dalam proses pembuatan PCB. Kajian ini mengimplementasikan PCB dengan proses screen printing yang menggunakan aplikasi LPISM (Liquid Photoimageable Solder Masks). Dimana dalam prosesnya pelapisan PCB dilakukan dengan mengendalikan jumlah cairan solder masks dalam sekali pelapisan menggunakan parameter yang tepat menggunakan metode Design of Experiment (DoE). Metode DoE ini bertujuan untuk memperbaiki kualitas PCB dengan biaya seminimal mungkin. DoE pada LPISM diterapkan di Teaching Factory Manufaktur Elektronika Politeknik Negeri Batam dengan tujuan untuk melindungi jalur PCB agar tidak terhubung satu dan yang lainnya, memberikan takaran yang tepat, serta mengurangi penggunaan solder masks lamination. Sehingga, laboran di Teaching Factory, Politeknik Negeri Batam dapat memproduksi PCB yang menggunakan metode LPISM dengan kualitas sesuai standar. Dari hasil analisis, didapatkan sudut yang tepat untuk melakukan screen printing adalah antara $15^{\circ}-20^{\circ}$ agar menghasilkan screen yang tidak rusak. Selain itu, proses oven dapat menipiskan solder masks hingga 70 - 80\%. Sehingga dari hasil keseluruhan rangkaian percobaan, didapatkan data ke-24 yang dapat dijadikan rekomendasi karena telah sesuai dengan standar IPC-SM-840C, dengan hasil ketebalan solder masks yaitu $2,5 \mu \mathrm{m}$.
\end{abstract}

Kata kunci: DoE, LPISM, PCB, screen printing, solder masks

\begin{abstract}
This paper examines several variables to formulated the best parameters in the PCB manufacturing process. This study was implements a PCB with a screen printing process that uses the LPISM (Liquid Photoimageable Solder Mask) application. Where in the process PCB coating is done by connecting the amount of solder liquid mask in one coating using the right parameters using the Design of Experiment (DoE) method. This DoE method improves the quality of the PCB at the lowest possible cost. DoE on LPISM applied at the Teaching Factory Manufaktur Elektronika Politeknik Negeri Batam with the aim of protecting the PCB lines from being connected to one another, providing the right measurements, and using the use of laminated mask solder. Thus, Politeknik Negeri Batam Teaching Factory laboratory assistants can produce PCBs using the LPISM method with quality according to standards. From the analysis, obtained an appropriate angle for screen printing is between $15^{\circ}-20^{\circ}$ so that the screen is not damaged. In addition, the oven process can thin the solder mask up to 70-80\%. In accordance with the results of comprehensive testing, the 24th data obtained can be recommended because it fulfill the IPC-SM-840C standard, with the 2.5 um solder mask thickness.
\end{abstract}

Keywords: DoE, LPISM, PCB, screen printing, solder masks 


\section{Pendahuluan}

Perkembangan teknologi akan banyak melibatkan penggunaan perangkat elektronik. Sebelum diproduksi dalam skala industri, maka terlebih dahulu dibuat prototype-nya. Dalam sebuah rangkaian elektronik, perlu adanya komponen agar rangkaian tersebut berfungsi dengan baik. Komponen dan rangkaian tersebut membutuhkan suatu wadah untuk menghubungkan antara komponen satu dan lainnya. Papan Rangkaian Tercetak (PRT) atau sering disebut PCB (Printed Circuit Board). PCB adalah sebuah papan dilapisi tembaga yang merupakan wadah untuk komponen-komponen elektronika yang tersusun membentuk rangkaian elektronik atau tempat rangkaian elektronika yang menghubungkan komponen elektronik yang satu dengan lainnya tanpa menggunakan kabel.

PCB yang telah diproduksi, dilapisi oleh solder masks dengan menggunakan proses screen printing. Kelebihan menggunakan screen printing ini adalah menghasilkan PCB dalam jumlah besar dengan hanya menggunakan screen, dan dapat digunakan lebih dari sekali. Sedangkan solder masks adalah lapisan pada PCB yang menutupi lapisan atas atau bawah pada jalur-jalur tembaga untuk mempermudah proses solder dengan melindungi tembaga sebagai konduktor agar komponen satu dan lainya tidak saling terhubung dan dapat mengurangi kemungkinan terjadinya arus pendek.

Teknologi solder masks yang biasanya dipakai di Teaching Factory Manufacturing of Electronics (TFME), Politeknik Negeri Batam adalah dengan melaminasi atau solder masks lamination. Teknologi ini memiliki kelemahan yaitu, solder masks tidak tahan panas, daya simpan yang kurang, dan berbiaya mahal. Sehingga, sebagai alternatif dari metode sebelumnya, peneliti mencoba untuk menggunakan aplikasi Liquid Photoimageable Solder Masks (LPISM) dan metode Design of Experiment (DoE) agar dapat memenuhi standar IPC-SM-840C.

Pada riset ini, implementasi PCB melalui proses screen printing dengan dilapisi oleh solder masks yang menggunakan aplikasi LPISM. Dalam penerapannya, PCB dilapisi dengan mengendalikan jumlah cairan solder masks dalam sekali pelapisan menggunakan parameter yang tepat dengan metode DoE yang bertujuan untuk memperbaiki kualitas menggunakan biaya seminimal mungkin. Sebelumnya pernah dilakukan beberapa riset menggunakan liquid photoimageable, diantaranya: liquid UV photoimageable Error! Bookmark not defined.; dan liquid photoimageable pada etching resist ink [2]. Selain itu, liquid photoimageable untuk solder mask [3] dan komposisi solder resist ink [4] telah terdaftar patennya di Amerika Serikat. Pada riset ini, LPISM akan diterapkan di TFME Politeknik
Negeri Batam dengan tujuan untuk menemukan takaran yang tepat, serta mengurangi penggunaan solder masks lamination. Sehingga, laboran di TFME Politeknik Negeri Batam dapat memproduksi PCB menggunakan metode LPISM dengan kualitas yang baik.

\section{Studi Literatur}

\subsection{Design of Experiment (DoE)}

Untuk menentukan parameter yang tepat dalam proses solder mask, maka metode yang tepat pula harus digunakan. Metode yang bertujuan untuk memperbaiki kualitas dengan biaya seminimal sehingga dalam menentukan parameter digunakanlah sistem yang disebut Design of Experiment (DoE). Riset menggunakan DoE pernah dilakukan sebelumnya, seperti: untuk mencari nilai optimum dari parameter solder paste printing [5]; dan pencetakan film tebal untuk substrat keramik pada proses screen printing-nya [6].

DoE adalah kajian mengenai penentuan kerangka dasar kegiatan pengumpulan informasi terhadap objek yang memiliki variasi, berdasarkan prinsip-prinsip statistika. DoE ini digunakan sebagai alat untuk merancang suatu eksperimen dengan kaidah-kaidah statistik untuk mendapatkan hasil yang optimal. Desain yang dimaksud adalah segala prosedur yang sifatnya sistematik, dilakukan dalam kondisi terkontrol untuk menemukan efek-efek yang belum diketahui, untuk menguji atau mematangkan suatu hipotesis. Ketika menjalankan proses analisis, eksperimen kerap digunakan untuk mengevaluasi variabel yang memiliki impact signifikan terhadap hasil akhir, dan mengetahui level variabel harus diperbaiki untuk memperoleh hasil yang diharapkan. Dalam metode Taguchi ada tiga tahap dalam mengoptimasi produk yaitu :

a. System Design

Tahap pertama untuk mendesain dan memunculkan ide-ide, metode dan untuk menjawab hasil hipotesis atau untuk meningkatkan kualitas produk.

\section{b. Parameter Design}

Tahap ini merupakan pembuatan secara fisik atau prototipe secara matematis berdasarkan tahap sebelumnya melalui percobaan secara statistik. Tujuannya adalah mengidentifikasi setting parameter yang akan memberikan performansi rata-rata pada target dan menentukan pengaruh dari faktor gangguan pada variasi dari target.

\section{c. Tolerance Design}

Penentuan toleransi dari parameter yang berkaitan dengan dampak atau output yang dihasilkan. Pada tahap ini, kualitas ditingkatkan dengan mengetatkan toleransi pada parameter atau proses untuk mengurangi terjadinya variabilitas.

\subsection{Liquid Photoimageable Solder Masks (LPISM)}


Teknologi LPISM pertama kali dikembangkan pada tahun 1980. Jenis LPISM yaitu solder masks dalam bentuk cair (liquid) yang apabila telah dilapisi pada PCB dan dipengaruhi oleh suhu dan pencahayaan sekitarnya akan menjadi solid tetapi dalam bentuk yang tipis [7].

Solder mask adalah lapisan polimer pernis tipis yang biasanya diaplikasikan untuk melindungi jalur tembaga pada PCB dari oksidasi dan mencegah saling terhubungnya kaki-kaki komponen satu dan komponen lain nya yang memiliki jarak berdekatan, dikarenakan jalur tembaga adalah bagian konduktor yang apabila gumpalan solder mengenai jalur tembaga lain akan merusak komponen lainya. Untuk melapisi PCB dengan solder masks harus memperhatikan tebal dan tipisnya pelapisan. Sifat solder masks yang permanen, yang disebabkan oleh proses UV atau expose film ke PCB, sehingga menyebabkan solder masks "masak" atau mengeras. Apabila terjadi kesalahan pada saat proses penyolderan, sangat sulit untuk mengkikis atau membersihkan lapisan solder masks yang sangat tebal, dan akan sangat sulit untuk proses penyolderan. Kesalahan yang sangat sederhana ini, mengharuskan mengganti penggantian papan PCB yang baru. Berdasarkan standar oleh The Institute for Interconnecting And Packaging Electronic Circuits IPC-SM-840C dan IPC-SM-840D tentang Qualification and Perfomance of Permanent Solder Mask dan oleh ketebalan lapisan Solder Masks pada PCB adalah $0.0025 \mathrm{~mm}$ atau $2.5 \mu$ [8], [9].

\section{Metode Penelitian}

\subsection{Rangkaian Percobaan}

Rangkaian Percobaan ini merupakan hasil produksi Teaching Factory Manufacturing of Electronics (TFME) Politeknik Negeri Batam, yang mana pada proses solder masks-nya menggunakan laminate solder mask. Rangakaian PCB ini digunakan sebagai bahan ajar karena desain komponennya dibutuhkan dan sudah mencakup untuk sertifikasi dari skema Inspeksi dan Rework PCB Assembly dari LSP P1 Politeknik Negeri Batam. Dalam satu ukuran PCB A4 210 x 297 mm dapat memuat sembilan PCB.
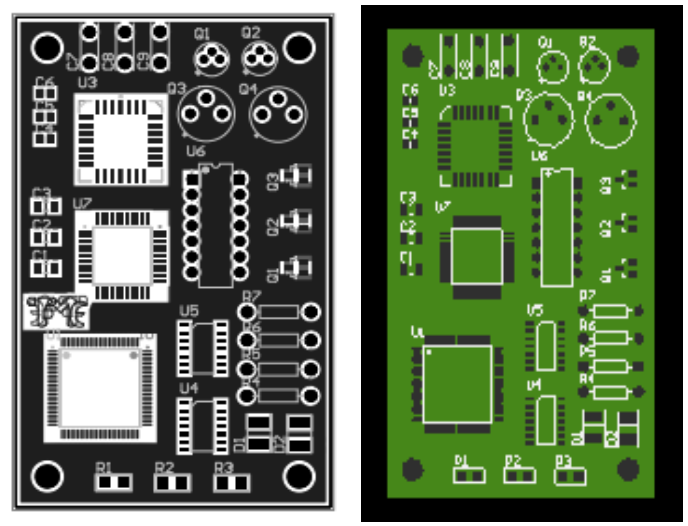

Gambar 1 PCB untuk Sertifikasi Inspeksi dan Rework PCB Assembly

\subsection{Sistem Kerja}

Dengan pengaplikasian LPISM proses yang dilewati lebih rumit, dalam prosesnya sebelum PCB dilapisi oleh solder masks, PCB akan melewati beberapa tahap, yang akan dijelaskan pada gambar berikut:

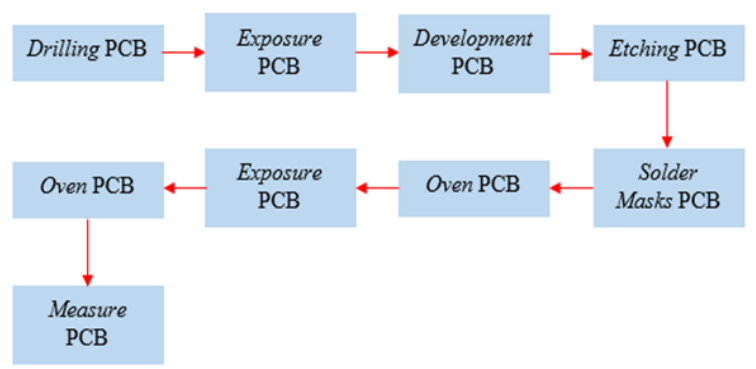

Gambar 2 Blok Diagram Langkah Kerja Percobaan

\subsection{Drilling $\mathrm{PCB}$}

Setelah PCB melewati proses brushing, PCB akan memasuki tahap drilling atau pengeboran yang menggunakan aplikasi RoutePro 2008.

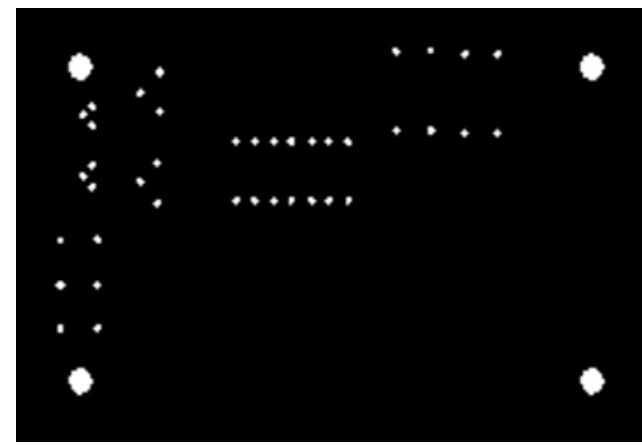

Gambar 3 Rangkaian untuk Proses Drilling

Pada aplikasi akan ditampilkan mata bor untuk proses drilling agar sesuai dengan pad hole pada IC, atau pad komponen lainnya. Pada tool in use sebelah kanan aplikasi akan jelas terlihat diameter mata bor yang digunakan. Pada gambar 4 ditunjukkan aplikasi untuk drilling pada kolom sebelah kanan merupakan mata drilling yang akan digunakan.

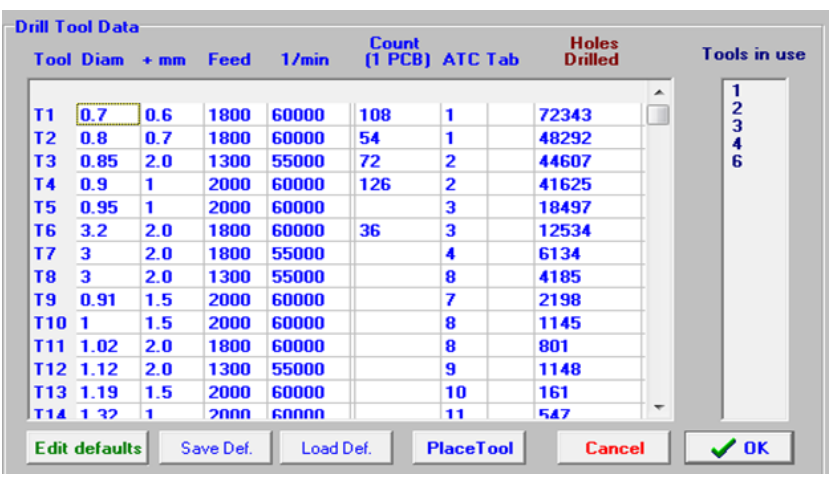

Gambar 4 Diameter Mata Bor untuk Proses Drilling 


\subsection{Exposure PCB}

Pada proses exposure atau expose PCB, digunakan sebuah film yang akan diletakkan pada PCB dan disinari oleh UV untuk mencetak rangkaian pada PCB. Untuk rangkaian seperti pada gambar 5 di bawah membutuhkan waktu sekitar 15 - 30 detik.

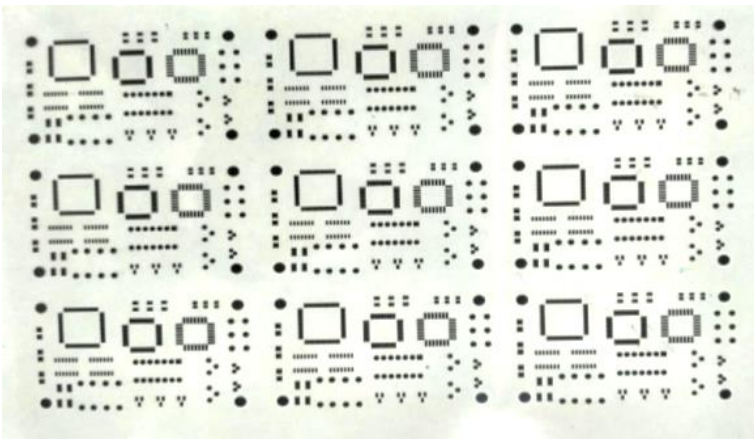

Gambar 5 Film untuk Mencetak Rangkaian pada PCB

\subsection{Development $\mathrm{PCB}$}

Pada proses development menggunakan larutan $\mathrm{NaCO}_{3}$ (sodium karbonat). PCB akan dilarutkan atau dibersihkan dari bagian yang terpapar sinar UV. Larutan development yang bewarna biru ini akan menunjukkan hasil dari proses UV, pada bagian pad IC atau komponen lainnya akan meluruh.

\subsection{Etching $\mathrm{PCB}$}

PCB etching adalah suatu proses untuk membuang bagian timah yang tidak dibutuhkan dengan menggunakan larutan menggunakan larutan ferric chloride $\left(\mathrm{FeCl}_{3}\right)$. Dimana waktu yang dibutuhkan untuk proses etching plat PCB pemanasan dengan stirer 5 menit lebih cepat dibandingkan pemanasan tanpa stirer[10]. Hasil yang didapat, ditunjukkan pada gambar 6, adalah rangkaian skematik yang telah tercetak di papan PCB kosong dapat diproses agar terbentuk jalur PCB nya.

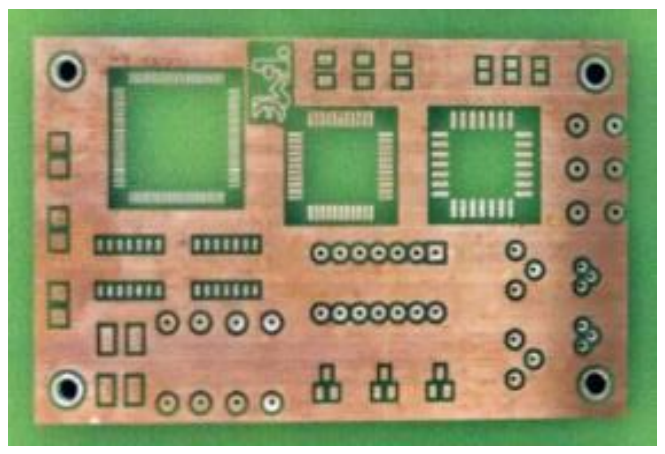

Gambar 6 Hasil Proses Etching PCB

\subsection{Soldermask PCB}

Setelah proses etching selesai, PCB akan langsung disapu dengan solder masks di semua permukaan. Dalam implementasinya, proses solder masks ini menggunakan mesin screen printing atau mesin sablon. Untuk proses meratakan solder masks ditentukan variabel dalam menyesuaikan dengan kondisi mesin sebagai berikut :

1. Tebal squeegee : $9,27 \mathrm{~mm}$

2. Tinggi squeegee : $1,84 \mathrm{~cm}$

3. Panjang squeegee : $39,5 \mathrm{~cm}$

4. Tinggi gagang squeegee $: 3,8 \mathrm{~cm}$

5. Jarak antara screen ke PCB : 3,63 mm

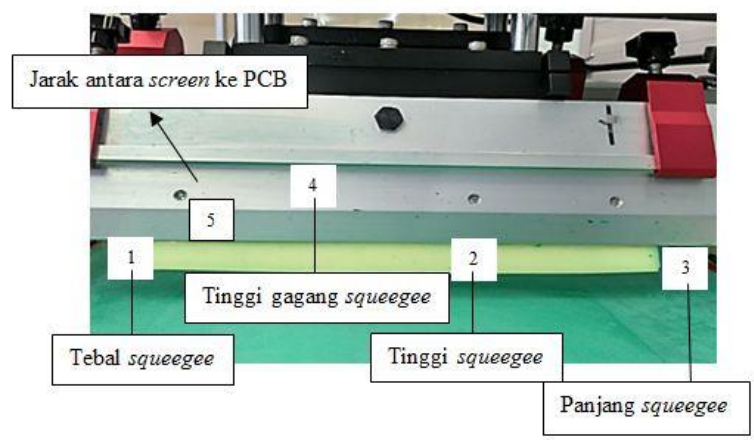

Gambar 7 Bagian Squeegee pada Mesin Screen Printing

Pada gambar 7 ditunjukkan bagian-bagian squeegee pada mesin screen printing, yang mana pengaturan posisi telah disesuaikan dengan proses percobaan. Pada gambar dapat dilihat ada jarak antara screen dengan PCB, ketika squeegee menyapu permukaan PCB dengan solder masks PCB akan disedot oleh vacuum, agar cat dapat merata dan tidak lengket atau menempel pada screen saat frame mesin diprogram naik.

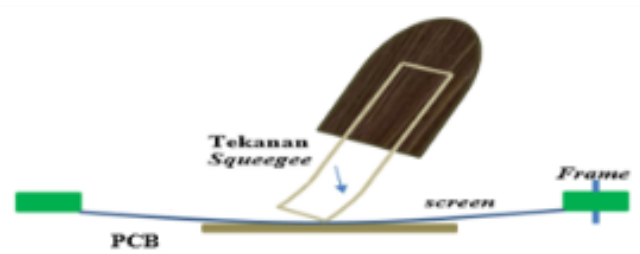

Gambar 8 Pergerakan Squeegee Terhadap Screen

Gambar 8 menunjukkan bagaimana pengaruh putaran skala squeegee mesin yang mengakibatkan turunnya squeegee sehingga menimbulkan tekanan terhadap screen. Pada gambar tersebut dapat dilihat bagaimana screen berpengaruh terhadap penyapuan oleh squeegee. Screen yang materialnya lebih fleksibel akan mengikuti tekanan squeegee.

\subsection{Oven $\mathrm{PCB}$}

Proses oven PCB atau predry dilakukan dengan tujuan agar solder masks matang atau mengeras pada PCB. Prosesnya, PCB dipanggang dengan suhu $72-76{ }^{\circ} \mathrm{C}$ dalam waktu 30 menit.

\subsection{Exposure PCB}

Agar pad pada PCB tidak terhubung satu dengan lainnya, dilakukan tahap penyinaran UV sekali lagi setelah proses solder masks, untuk menempelkan film 
yang berbeda yaitu top layer. Area yang tidak tertutup oleh film akan mengeras, sehingga solder mask matang.

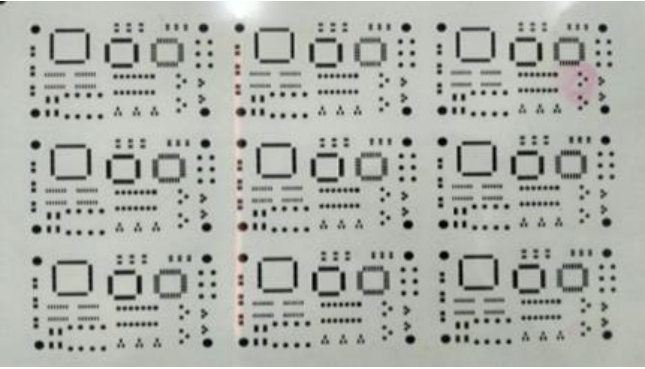

Gambar 9 Film untuk UV Solder Masks

\subsection{Development $\mathrm{PCB}$}

Pada proses develop ini bagian yang terlapisi solder mask tidak akan terkikis. Hanya membersihkan bagian yang terpapar sinar UV pada saat proses expose, lalu akan dilanjutkan dengan membilas dengan air biasa.

\subsection{Oven $\mathrm{PCB}$}

Pada proses oven, PCB akan dimasukkan ke dalam oven dengan suhu $150^{\circ} \mathrm{C}$, untuk mematangkan solder masks sekaligus untuk menguji ketahanan solder masks. Hasil akhir dari PCB ditunjukkan pada gambar 10.

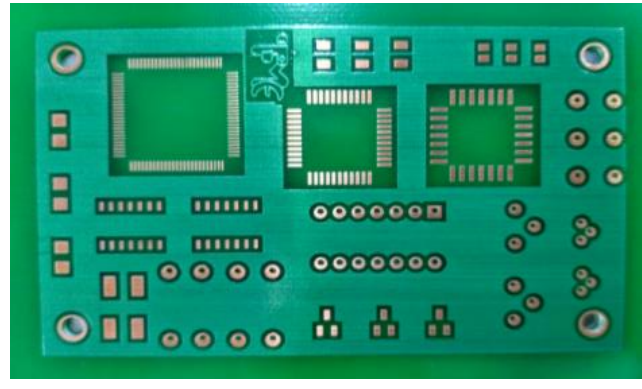

Gambar 10 Hasil Akhir PCB

\subsection{Measure PCB}

Pada bagian akhir, PCB akan diukur ketebalan solder masks menggunakan alat, seperti pada gambar 11, yang disebut depth and height measure scope untuk mengetahui hasilnya mendekati standar atau sesuai standar IPC-SM-840C.

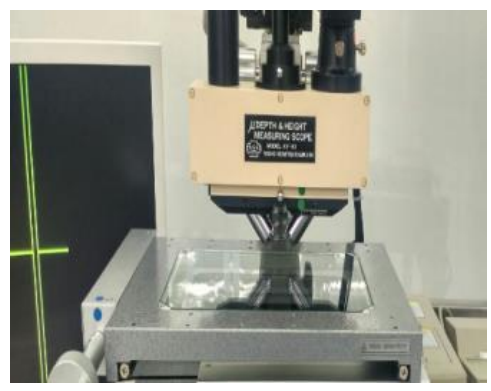

Gambar 11Alat pengukur tebal PCB

\section{Hasil dan Pembahasan}

\subsection{Proses Pengambilan Data}

Pada pengambilan data Design of Experiment (DoE) Liquid Photoimageable Solder Masks (LPISM), film akan memasuki proses expose pada screen. Pada awal percobaan, cairan solder masks dicampurkan dengan aseton $\left(\mathrm{C}_{3} \mathrm{H}_{6} \mathrm{O}\right)$ agar solder mask yang semulanya kental menjadi sedikit cair. Tetapi, mencampurkan aseton menyebabkan solder masks menjadi lebih mudah kering dan merusak screen sehingga screen menjadi "buntu" dalam artian solder mask tidak dapat tercetak pada permukaan PCB. Sebelum proses solder masks PCB dilakukan dengan mesin screen printing, percobaan dilakukan secara manual untuk mengetahui hasil dari pengaruh cairan solder mask terhadap screen dan PCB apakah menjiplak pada PCB atau akan buntu dan menempel pada screen.

Selanjutnya PCB yang sudah di solder masks tersebut, akan di oven dalam suhu $72-76^{\circ} \mathrm{C}$ selama 30 menit. Setelah itu, PCB akan diukur ketebalan solder masks dengan menggunakan alat yang disebut depth and heigh measure scope.

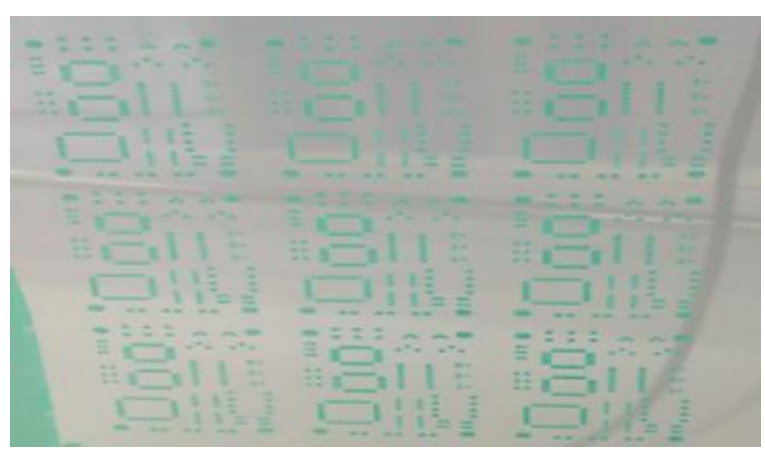

Gambar 12 Screen Tercetak

Pada gambar 12 merupakan hasil dari film yang telah tercetak dan telah disinari (expose) ke screen. Film yang digunakan adalah film negatif. Sehingga yang terjiplak pada screen adalah bagian yang akan disapu oleh solder masks saja. Hasil penyapuan solder masks dapat dilihat pada gambar 13 seperti berikut.

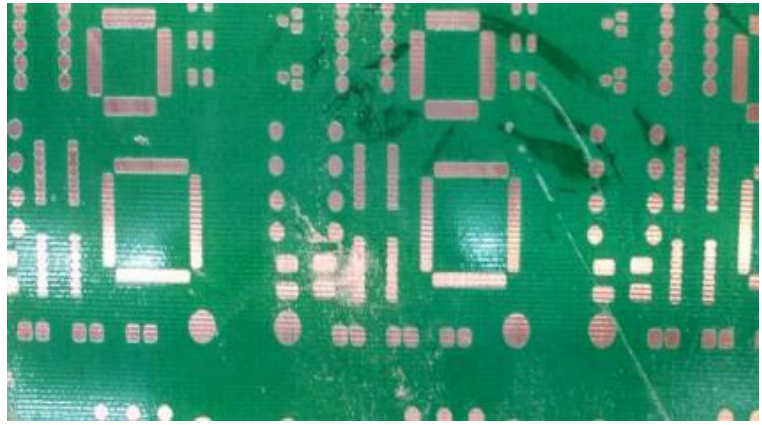

Gambar 13 Hasil PCB Setelah Penyapuan Solder Masks

Selanjutnya hasil PCB ini akan di ukur ketebalannya menggunakan alat depth and heigh measure scope. Pada proses pengambilan data, akan diambil beberapa 
titik untuk dijadikan bahan pengukuran. Pada pelapisan solder maks yang akan diukur adalah daerah efektif, yaitu daerah yang hasil pelapisanya secara "kasat mata" tampak lebih bagus, tidak ada kecacatan.

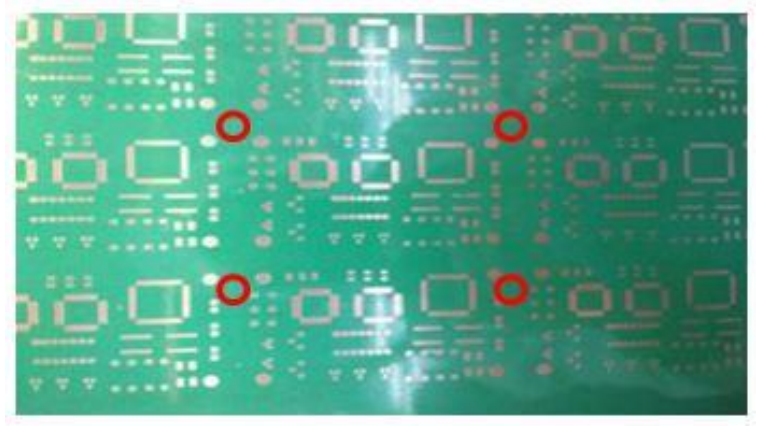

Gambar 14 Daerah Efektif Pelapisan Solder Masks PCB

Pada gambar 14 merupakan PCB yang berukuran 2 Pada gambar 14 terlihat lingkaran bewarna merah, yang merupakan titik - titik pengambilan data dari daerah efektif PCB yang terlapisi oleh solder mask untuk diukur ketebalannya. Setelah diketahui ketebalan solder masks di setiap titik maka akan dihitung hasil rata-rata pengukuran tersebut dan disimpulkan sebagai ketebalan solder masks secara keseluruhan.

Daerah efektif biasanya ada pada daerah tengah PCB, dan titik pengukuran akan diambil pada daerah tersebut, dikarenakan pada tepi atau awal pelapisan solder masks akan ada penyesuaian dari variabel yang diberikan dengan papan PCB.

\subsection{Tabel DoE Liquid Photoimageable Solder Masks PCB}

Pembuatan tabel dibutuhkan untuk menguraikan interaksi antara variabel satu dan lainnya. Pada percobaan DoE ini, percobaan dilakukan sebanyak 81 kali percobaan. Karena terdiri dari empat variabel yang mana masing - masing variabel memiliki tiga kontrol berbeda, yang diuraikan pada tabel I.

TABEL I

VARIABEL PERCOBAAN

\begin{tabular}{ll}
\hline \hline \multicolumn{1}{c}{ Variabel } & Kontrol \\
\hline Variabel 1 & 21 gram \\
Kandungan solder masks (gram) & 20 gram \\
& 24 gram \\
\hline Variabel 2 & 5 gram \\
Kandungan hardener $($ gram) & 4 gram \\
& 1 gram \\
\hline Variabel 3 & $25^{0}$ \\
Sudut (dalam derajat) & $20^{0}$ \\
& $15^{0}$ \\
\hline \multirow{2}{*}{ Variabel 4 } & $800 \mu$ \\
Putaran skala squeegee mesin (dalam mikron) & $900 \mu$ \\
\end{tabular}

Dimana, 81 kali perobaan didapat perhitungan berikut:

Percobaan $=x^{n}$

Percobaan $=3^{4}$

Percobaan $=81 \mathrm{kali}$

$\mathrm{x}=$ jumlah kontrol dalam variabel

\subsection{Verifikasi Hasil}

Verifikasi hasil dilakukan untuk memastikan keakuratan data. Data yang diambil pada verifkasi ini adalah angka yang mendekati ketebalan dari standar IPC - SM - 840C yaitu $2.5 \mu \mathrm{m}$. Angka yang akan di lakukan sebagai verifikasi hasil dapat terlihat pada tabel II berikut.

TABEL II

DATA VERIFIKASI HASIL

\begin{tabular}{llllll}
\hline \multicolumn{1}{c}{ Percobaan ke- } & 16 & 18 & 24 & 26 \\
\hline Kandungan Solder & 21 gram & $\sqrt{ }$ & $\sqrt{ }$ & $\sqrt{ }$ & $\sqrt{ }$ \\
Masks & 20 gram & & & & \\
& 24 gram & & & & \\
\hline Kandungan & 5 gram & & & & \\
Hardener & 4 gram & $\sqrt{ }$ & $\sqrt{ }$ & & \\
& 1 gram & & & $\sqrt{ }$ & $\sqrt{ }$ \\
\hline Sudut Squeegee & $25^{\circ}$ & & & & \\
& $20^{\circ}$ & & & $\sqrt{ }$ & \\
& $15^{\circ}$ & & & & $\sqrt{ }$ \\
\hline Putaran Skala & $800 \mu$ & $\sqrt{ }$ & & & \\
Squeegee Mesin & $900 \mu$ & & & & $\sqrt{ }$ \\
& $1000 \mu$ & & $\sqrt{ }$ & $\sqrt{ }$ & \\
\hline Pengukuran tebal & Titik 1 & 4 & 2 & 2 & 1 \\
Solder Masks & Titik 2 & 6 & 2 & 7 & 3 \\
& Titik 3 & 1 & 3 & 2 & 4 \\
& Titik 4 & 5 & 3 & 3 & 1 \\
\hline & Hasil Rata-rata & \multirow{2}{*}{4} & \multirow{2}{*}{2,25} & 3,5 & 2,25 \\
\hline \hline
\end{tabular}

Mean $=\frac{x_{1}+x_{2}+x_{3}+\ldots+x_{n}}{n}$

$\operatorname{Variance}\left(s^{2}\right)=\frac{\sum(x-\bar{x})^{2}}{(n-1)}$

Standard Error $(\mathrm{SE})=\sqrt{\frac{S^{2}}{n}}$

Standard Deviation $=\sqrt{s^{2}}$

$\mathrm{x}=$ data

$\mathrm{n}=$ jumlah data

Dari hasil verifikasi data ke-16,data ke-18,data ke-24, dan data ke-26 tersebut dapat dilihat bahwa standar 
TABEL III

PERCOBAAN VERIFIKASI DATA KE-16; DATA KE-18; DATA KE-24; DAN DATA KE-26

\begin{tabular}{|c|c|c|c|c|c|c|c|c|c|c|}
\hline & & P1 & $\mathrm{P} 2$ & $\mathrm{P} 3$ & $\mathrm{P} 4$ & P5 & Mean & $\mathrm{S}^{2}$ & SD & SE \\
\hline \multirow{5}{*}{ Data ke - 16} & Titik 1 & 2 & 4 & 4 & 2 & 4 & \multirow{5}{*}{3,95} & \multirow{5}{*}{1,62} & \multirow{5}{*}{1,27} & \multirow{5}{*}{0,28} \\
\hline & Titik 2 & 5 & 4 & 6 & 6 & 3 & & & & \\
\hline & Titik 3 & 4 & 3 & 2 & 3 & 6 & & & & \\
\hline & Titik 4 & 4 & 5 & 3 & 5 & 4 & & & & \\
\hline & Rata-rata & 3,75 & 4 & 3,75 & 4 & 4,25 & & & & \\
\hline \multirow{5}{*}{ Data ke -18} & Titik 1 & 2 & 2 & 1 & 2 & 1 & \multirow{5}{*}{2,5} & \multirow{5}{*}{0,68} & \multirow{5}{*}{0,82} & \multirow{5}{*}{0,18} \\
\hline & Titik 2 & 3 & 3 & 3 & 3 & 4 & & & & \\
\hline & Titik 3 & 3 & 2 & 4 & 3 & 3 & & & & \\
\hline & Titik 4 & 2 & 2 & 3 & 2 & 2 & & & & \\
\hline & Rata-rata & 2,5 & 2,25 & 2,75 & 2,25 & 2,5 & & & & \\
\hline \multirow{5}{*}{ Data ke - 24} & Titik 1 & 1 & 4 & 3 & 3 & 1 & \multirow{5}{*}{3,5} & \multirow{5}{*}{2,68} & \multirow{5}{*}{1,63} & \multirow{5}{*}{0,36} \\
\hline & Titik 2 & 7 & 4 & 2 & 2 & 4 & & & & \\
\hline & Titik 3 & 2 & 3 & 4 & 3 & 6 & & & & \\
\hline & Titik 4 & 4 & 4 & 5 & 6 & 2 & & & & \\
\hline & Rata-rata & 3,5 & 3,75 & 3,5 & 3,5 & 3,25 & & & & \\
\hline \multirow{5}{*}{ Data ke - 26} & Titik 1 & 2 & 3 & 3 & 2 & 2 & \multirow{5}{*}{2,4} & \multirow{5}{*}{1,2} & \multirow{5}{*}{1,09} & \multirow{5}{*}{0,24} \\
\hline & Titik 2 & 5 & 2 & 4 & 3 & 1 & & & & \\
\hline & Titik 3 & 1 & 1 & 4 & 2 & 3 & & & & \\
\hline & Titik 4 & 2 & 2 & 1 & 2 & 3 & & & & \\
\hline & Rata-rata & 2,5 & 2 & 3 & 2,25 & 2,25 & & & & \\
\hline
\end{tabular}

*Pengukuran dalam satuan $\mu \mathrm{m}$ (mikrometer); Pn adalah Percobaan

error yang didapatkan hasilnya lebih kecil dari mean, maka nilai mean tersebut dapat digunakan sebagai representasi dari keseluruhan data. Tetapi, diantara semua data yang telah diuji verifikasi hasilnya,ditunjukkan pada tabel III, data ke - 24 memiliki nilai error yang sangat tinggi. Dapat disebabkan oleh penyimpangan data dari nilai mean.

\subsection{Proses Akhir}

Pada pengukuran final, sesuai dengan blok diagram gambar 2, proses ini merupakan proses lengkap PCB dengan LPISM. PCB akan mengalami dua kali proses oven yaitu setelah dilapisi oleh solder masks dan setelah proses development PCB. Pada Data Sheet solder masks yang digunakan solder masks dapat mengalami penyusutan hingga $70-80 \%$ [11]

Penyusutan $=\frac{n}{100} \times \bar{n}$

$\mathrm{n}=$ penyusutan

$\bar{n}=$ hasil data pengukuran

Angka penyusutan dihitung dari hasil pengukuran screen tercetak. Dikarenakan pada proses screen tercetak PCB hanya mengalami satu kali proses oven, yang mana proses tersebut dilakukan untuk mengeringkan PCB yang masih basah.
Pada tabel IV berikut ini menunjukkan perbandingan antara PCB yang menggunakan screen tercetak (data yang diambil adalah data sebelum verifikasi) dan PCB yang melewati proses secara lengkap.

TABEL IV

PERBANDINGAN HASIL PCB SOLDER MASK

\begin{tabular}{llcc}
\hline \hline & Titik Efektif & Screen Tercetak & $\begin{array}{c}\text { Proses } \\
\text { Lengkap }\end{array}$ \\
\hline \multirow{5}{*}{ Data ke - 16 } & Titik 1 & 4 & 4 \\
& Titik 2 & 6 & 3 \\
& Titik 3 & 1 & 2 \\
& Titik 4 & 5 & 2 \\
\cline { 2 - 4 } Data ke - 18 & Rata-rata & 4 & 3 \\
\hline & Titik 1 & 2 & 2 \\
& Titik 2 & 2 & 1 \\
& Titik 3 & 3 & 1 \\
& Titik 4 & 2 & 2 \\
\cline { 2 - 4 } Data ke-24 -24 Rata-rata & 2,25 & 1,5 \\
\hline & Titik 1 & 2 & 2 \\
& Titik 2 & 7 & 3 \\
& Titik 3 & 2 & 3 \\
& Titik 4 & 3 & 1 \\
\cline { 2 - 4 } & Rata-rata & 3,5 & 2,5 \\
\hline \multirow{5}{*}{ Data ke - 26 } & Titik 1 & 2 & 1 \\
& Titik 2 & 2 & 1 \\
& Titik 3 & 3 & 2 \\
\cline { 2 - 4 } & Titik 4 & 2 & 1,5 \\
\cline { 2 - 4 } & Rata-rata & 2,25 & \\
\hline \hline
\end{tabular}

*Pengukuran dalam satuan $\mu \mathrm{m}$ (mikrometer)

Setelah mengetahui hasil screen tercetak dan proses lengkap, maka akan didapat penyusutan yang mendekati antara $70-80 \%$, ditunjukkan pada tabel V, yang disebabkan oleh proses oven dengan suhu 1500. 
TABEL V

HASIL PENYUSUTAN

\begin{tabular}{ccccc}
\hline \hline \multirow{2}{*}{ Penyusutan } & \multicolumn{4}{c}{ Data ke- } \\
\cline { 2 - 5 } & 16 & 18 & 24 & 26 \\
\hline $70 \%$ & 2,8 & 1,57 & 2,45 & 1,57 \\
$75 \%$ & 3 & 1,68 & 2,62 & 1,68 \\
$80 \%$ & 3,2 & 1,8 & 2,8 & 1,8 \\
\hline \hline
\end{tabular}

*Pengukuran dalam satuan $\mu \mathrm{m}$ (mikrometer)

\subsection{Analisis}

Parameter pertama yang paling mungkin dapat ditentukan adalah sudut. Sudut yang baik digunakan adalah $15^{0}-20^{\circ}$, karena apabila menggunakan sudut di bawah $15^{0}$ maka dapat merusak screen. Hal tersebut disebabkan oleh posisi squeegee yang terlalu tegak dan sejajar dengan screen. Sedangkan jika menggunakan sudut lebih dari $20^{\circ}$, maka ada kemungkinan solder mask tidak terjiplak ke PCB. Hal tersebut dapat terjadi karena posisi yang sedikit miring atau bahkan terlalu miring jika dikondisikan dengan setting posisi squeegee mesin dan screen.

Semua variabel berpengaruh kepada hasil proses yang didapatkan, karena jika suatu variabel tidak dipasangkan dengan variabel lainnya dengan tepat, dapat menghasilkan solder masks yang terlalu tebal pada papan PCB atau bias lebih tipis pada papan PCB yang memungkinkan tidak sesuai standar IPC-SM-840C. Selama percobaan, terdapat hambatan yang didapatkan, salah satunya adalah pada saat melakukan proses oven yang penggunaanya tidak efektif yang mengakibatkan adanya penurunan suhu.

Percobaan menggunakan sembilan PCB yang digunakan terus menerus untuk melakukan 81 kali percobaan data. Sehingga pada saat membersihkan PCB menggunakan aseton, apabila tidak dilakukan dengan baik maka dapat meninggalkan sisa - sisa solder masks yang berdampak pada ketebalan solder masks pada PCB dan berpengaruh pada data yang didapatkan.

Dari hasil data ke - 24, didapat hasil yang sesuai dengan standar IPC-SM-840C, tetapi pada verifikasi hasil data, didapat standar deviasinya adalah 1,63 dan standar error-nya adalah 0,36. Data ke-24 memiliki standar deviasi dan standar error yang sanggat tinggi dibandingkan dengan ketiga data lainnya yang telah diverifikasi hasilnya. Tetapi, data ke-24 memiliki sudut yang sesuai dengan kriteria "baik" untuk proses produksi yaitu sudut $20^{\circ}$, sedangkan data ke-16, data ke-18, dan data ke-26 menggunakan sudut $15^{\circ}$ yang berarti merupakan mendekati sudut yang dapat merusak screen.
Hasil dari verifikasi data pada data ke-24 dapat disebabkan oleh beberapa faktor berikut:

1. Permukaan squeeegee yang tidak rata karena masih adanya sisa solder mask yang tidak terjiplak seutuhnya ke PCB, sehingga ada permukaan $\mathrm{PCB}$ yang tebal dan tipis dan permukaan PCB yang tidak rata;

2. Screen yang buntu karena proses sebelumnya;

3. Proses oven yang tidak efektif;

4. Solder masks yang digunakan kadaluarsa, sehingga viskositasnya telah berubah.

\subsection{Rekomendasi}

Dari percobaan yang didapat data ke-24 memiliki hasil yang sesuai dengan standar IPC-SM-840C yaitu dengan ketebalan solder masks 2,5 $\mu \mathrm{m}$. Pada data ke 24 didapat variabel sebagai berikut:

1. Kandungan solder masks : 21 gram

2. Kandungan hardener: 1 gram

3. Sudut squeegeee: $20^{\circ}$

4. Putaran skala squeegee mesin : $1000 \mu$

5. Tidak mencampurkan aseton dalam cairan solder masks

\section{Kesimpulan}

Berdasarkam hasil analisis DoE dari Liquid Photoimageable Solder Masks PCB yang telah dilakukan, didapatkan simpulan yaitu: putaran skala squeegee; sudut pada mesin screen printing; kandungan solder masks; dan hardener mempengaruhi hasil dari solder masks yang terjiplak ke PCB. Sudut yang tepat untuk melakukan screen printing adalah antara $15^{0}-20^{\circ}$, sehingga dengan sudut tersebut akan mengahsilkan screen yang tidak rusak. Selain itu, hasil analisis menunjukkan bahwa proses oven dapat menipiskan solder masks hingga 70 - 80\%. Sehingga didapatkan data ke-24 yang dapat dijadikan rekomendasi karena telah sesuai dengan standar IPC-SM-840C.

\section{Referensi}

[1] Zhai-min, Wang; Jiang, Cheng; Xiu-fang, Wen; Pi-hui, Pi; Zhuo-ru, Yang, "Research Progress of Liquid UV Photo-imageable Ink for Printed Circuit Board," Research Institute of Chemical Engineering, South China University of Technology, Guangzhou, Mar. 2004.

[2] Liang, Zhou; Jiang, Chen; Zhuoru, Yang, "Progress in Research on Liquid Photo Imageable Etching Resist Ink," Research Institute of Chemical Engineering, South China University of Technology, Guangzhou, Jul. 2002. 
[3] Yanagawa, Makoto; Santo, Shinji, "Photopolymerizable Liquid Photoimageable Solder Mask," US5100767A.

[4] Chihara, Machio; Funahashi, Mitsukazu, "Alkaline Developable Liquid Photoimageable Solder Resist Ink Composition," US4933259A.

[5] Gopal, Sekharan; Mohd Rohani, Jafri; Mohd Yusof, Sha'ri; Abu Bakar, Zailis, "Optimization of Solder Paste Printing Parameters Using Design of Experiments (DOE)," Jurnal Teknologi (Sciences and Engineering) UTM, vol. 43, Dec. 2005.

[6] Pan, Jianbiao; Tonkay, Gregory L.; Quintero, Alejandro, "Screen Printing Process Design of Experiments for Fine Line Printing of Thick Film Ceramic Substrates," Journal of Electronics Manufacturing, vol. 09, no. 03, pp. 203-213, 1999.

[7] Coates Circuit Products, "Liquid Photoimageable Solder Mask." [Online]. Available: https://www.coates.de/ccp/connections/liquid.pd f.
[8] The Institute for Interconnecting and Packaging Electronic Circuits, "IPC-SM-840C, Qualification and Performance of Permanent Solder Mask.” Jan-1996.

[9] The Institute for Interconnecting and Packaging Electronic Circuits, "IPC-SM-840D, Qualification and Performance of Permanent Solder Mask.” Apr-2007.

[10] B. Budiana, E. Aprilia, M. T. Ginting, and B. Sugandi, "Kajian Waktu Etsa dan Penurunan Massa PCB double Layar," JURNAL INTEGRASI, vol. 10, no. 2, pp. 86-91, Oct. 2018, doi: 10.30871/ji.v10i2.987.

[11] Onstantic Technology Co.,LTD., "Photoimageable Solder Resist Ink Data Sheeet: $\mathrm{R}$ - 500 GAH Series (2 component / liquid photoimageable solder mask)." . 